\title{
PAX5 and B-cell neoplasms: transformation through presentation
}

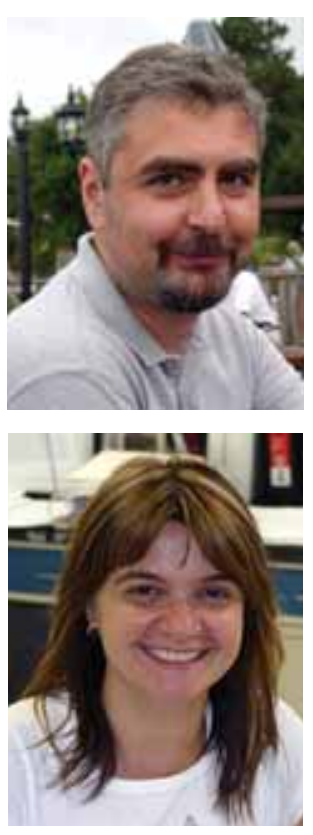

\section{Andrei Thomas Tikhonenko' \& D iana C ozma}

tAuthor for correspondence D epartment of Pathobiology and $M$ ari Lowe Center for Comparative O ncology, School of Veterinary $M$ edicine, U niversity of Pennsylvania, Philadelphia PA 19104-6051, USA Tel.: +1 2155735138 ; Fax: +1 215746 0380; andreit@mail.vet.upenn.edu

future, part of $\mathrm{fsg}$

\author{
'Most diffuse large B-cell \\ lymphomas and other \\ non-Hodgkin lymphomas are \\ derived from mature Bcells, which \\ express B-cell receptors and have \\ often undergone maturation in \\ germinal centers.'
}

What ever Pax5 soweth...

The salient features of B-cell development are immunoglobulin gene rearrangements, class switching recombinations (CSRs) and somatic hypermutations (SH M s). Collectively, these processes account for the diversity of antibodies, as well as for affinity maturation of antibodies in germinal centers. However, the propensity of $B$ cells to undergo genetic alterations has unintended consequences - that is, a high frequency of oncogenic events. These events clearly inform lymphomagenesis: translocated and otherwise altered genes inevitably turn out to be oncogenes playing an important role in tumor initiation. For example, Burkitt's and some diffuse large B-cell lymphomas (D LBCLs) carry the $t(8 ; 14)$ translocation that places the M YC protooncogene under control of the Igh enhancer (for a recent review see [1]).

Another transcription factor affected by translocations is Pax5. Pax5 belongs to a family of nine nuclear proteins that are thought to control the tissue-specific transcription necessary for many types of cell differentiation. Pax5 is the only family member found within the hematopoietic system, and its expression is restricted to certain stages during B-cell differentiation [2]. It is largely absent from multipotent progenitors and common lymphoid progenitors [3], but its expression is initiated in pre-pro-B cells and then maintained throughout subsequent stages of B-cell development [4] before it is downregulated in plasma cells [5]. However, Pax5 is unique among other lineage-specific transcription factors in that it is both a driving force behind and one of the primary beneficiaries (or perhaps sufferers) of genomic alterations.
Indeed, one of its important targets is the Rag-2 gene encoding recombination-activating protein $2[6,7]$. D uring $V_{H}-D J_{H}$ recombination, the RAG 1/RAG 2 complex introduces doublestranded DNA breaks that ultimately rejoin to generate functional heavy chain cassettes. The same process is thought to underlie illegitimate recombination, during which Ig heavy chain enhancers will be juxtaposed to one of the $B$-cell oncogenes such as $M$ yc, $B C l 2, B C l 1$ and so on. In addition to activating the Rag2 gene, Pax5 occupies $V_{H}$ genes in early human and mouse B-lineage cells, induces I gh locus contraction [8], and physically interacts with the RAG $1 /$ RAG 2 complex, thus promoting recombination events [9]. Importantly, the $\mathrm{V}_{\mathrm{H}}-\mathrm{D} \mathrm{J}_{\mathrm{H}}$ recombination cannot happen in the presence of lysine-9-methylated histone $\mathrm{H}_{3}$, and the removal of this inhibitory signal in B cells is an important function of Pax5 [10]. Consequently, only a minor fraction of lymphocytes in Pax5-null mice have completed $V_{H}-D J_{H}$ rearrangement and most are arrested at the earlier, pro-B stage [11]. Recent data indicate that Pax5 might also play a role in light chain locus contraction [12]. Additionally, Pax5 is known to be required for the expression of Ig [13], a slgM -associated signaling molecule, which is the key component of the $B$-cell receptor (BCR; reviewed in [14]).

CSR, which might also contribute to oncogenic translocations, and SH M are less wellunderstood processes. H owever, recent work has implicated activation-induced cytidine deaminase (AID) in both phenomena. Interestingly, Pax5 is known to activate AID [15,16] and can therefore contribute to $\mathrm{CSR}$ and $\mathrm{SHM}$ also. $O$ verall, while Pax 5 might be a guardian of $B$-cell identity [2], it is a curiously permissive one with respect to genome integrity.

..he shall also reap

The cruel irony is that while Pax5 loyally acts on behalf of $B$ cells to ensure their genetic diversity, it is one of the first to suffer from that diversity. Indeed, either an erroneous $V_{H}-D J_{H}$ rearrangement or CSR are likely responsible for the relatively rare [17], but persistent, $t(9 ; 14)$ ( $p 13 ; q 32)$ translocation [18-20] associated with aggressive 
B-cell non-H odgkin lymphomas [21]. This translocation usually brings together the coding sequences of PAX5 and a strong enhancer from the Igh locus, ensuring robust transcription of the translocated PAX5 allele. In addition to disturbing Pax5-guided gene expression during lymphocyte differentiation, the translocation can potentially lead to failed PAX 5 repression at the onset of plasma cell differentiation [2].

'In contrast, most of B-progenitor a cute lymphoblastic leukemia (so-called A1 and $A 2$ types) a re derived from immature pro- or pre-B-cells lacking B-cell receptors.'

In addition to genomic rearrangements, the Pax5 gene is also affected by SH M. In the highprofile 2001 study, more than $50 \%$ of human germinal center-derived D LBC Ls were found to contain mutations in the proto-oncogenes PIM , M YC, RhoH /T TF (ARHH) - and Pax5 [22]. In the latter, SH M were identified downstream of both transcription initiation sites, predominantly around exon $1 B$, at the frequency of 0.15 per $100 \mathrm{bp}$. Although three missense mutations were detected within the short coding portion of exon 1B, most of the changes involved $5^{\prime}$ untranslated and other noncoding sequences [22]. This distribution implied that the main consequence of these gain-of-function SH M s is transcriptional activation of Pax5 and, plausibly, B lymphomagenesis.

Two studies using shRNA-mediated gene knockdown appear to corroborate this notion. The RN Ai experiments were performed in vitro on two cell lines, SU D H L-4 and -6, belonging to the germinal center $B$ cell-like subclass of DLBCL [23]. In the first study, the authors achieved knockdown of the key downstream effector of Pax5 Iga (also known as CD 79a) [24]; in the second study, from our laboratory, the Pax5 gene itself was targeted [25]. Under both experimental conditions, decreases in cell accumulation were observed, supporting the oncogenic role of Pax5. H owever, other recent data suggest that the picture might be much more complicated.

Acute lymphoblastic leukemia versus non-Hodgkins lymphoma: why does it matter?

The surprising findings came from the analysis of B-progenitor acute lymphoblastic leukemia (B-ALL), a common pediatric malignancy. It turned out that Pax5 is important for B-ALL pathogenesis - but not in the way one would expect. In their December 2006 Blood paper, Bousquet et al. report a novel $t(7 ; 9)(q 11 ; p 13)$ translocation in two $B-A L L$ patients, resulting in the fusion of the Pax5 and elastin (ELN) genes [26]. Fusions between Pax5 and various translocation partners are not new. For example, the previously described $t(9 ; 12)(q 11 ; p 13)$ translocation generates a fusion transcription factor containing D N A-binding domains of both Pax5 and ets variant gene 6 (ET V6)/translocation, ets, leukemia (TEL) [27]. What is interesting regarding the Pax5-ELN fusion is that not only is it loss-of-function, but it also acts as a dominantnegative isoform in transient expression assays [26].

In parallel, Mullighan et al. embarked on the genome-wide analysis of B-ALL using highresolution SNP arrays and direct genome sequencing. Surprisingly, the two most commonly mutated genes were Pax5 and its upstream regulator, early B cell factor 1 (EBF 1 ) [28]. Again, the mutations identified were, without exception, loss-of-function: monoallelic deletions of EBF1 and Pax5, cryptic transloctions removing the Pax5 activation domain, frameshift mutations in Pax5, and so on. Importantly, both transient expression assays and the analysis of PAX5 target genes confirmed that Pax 5 function is consistently reduced (although not completely abolished) in B-ALL cases. The authors conclude that subtle changes in the dosage of PAX5, rather than its overexpression, underlie the pathogenesis of ALL [28]. While this might certainly be the case, an important question is whether gain-of-function mutations in the Pax5 gene play any role in B lymphomagenesis at all.

O ne possible answer is that it does, but only at certain stages of B-cell development. Most $D L B C L$ and other non-H odgkin lymphomas are derived from mature $B$-cells, which express $B C R$ and have often undergone maturation in germinal centers [29]. In contrast, most of B-ALL (socalled $A 1$ and $A 2$ types) are derived from immature pro- or pre-B-cells lacking BCR [30]. Given the contribution of Pax5 to BCR signaling (see above), it seems plausiblethat Pax5 can only exert its oncogenic effects when this pathway is functional. H owever, an experimental verification of this simple model has been slow in coming.

\section{A man or a mouse?}

$N$ eedless to say, dissecting the causative role of putative oncogenes in spontaneous human 
tumors can be tricky. However, the knockout/knock-in mouse technology tends to be helpful in this regard. With this goal in mind, the entire Pax5-coding sequence has recently been knocked into the Igh locus, thus recreating the $t(9 ; 14)$ translocation in the mouse. The animals did develop overt neoplasms, but rather unexpectedly developed $\mathrm{T}$, and not B lymphomas [31]. Apparently, the germline insertion of the Pax5 gene and its ensuing activation throughout the lymphoid system arrests T-cell development and leads to malignant $T$ lymphomas. This rather artificial system is nevertheless reminiscent of idiopathic activation of Pax5 in forebrain-derived astrocytomas [32] and a subset of highly malignant neuroblastoma cell lines [33].

However, to assess its role in B lymphomagenesis, new approaches were in order. O ur laboratory took advantage of a previously described cell line (Myc5) derived from a p53-null, Myc-overexpressing lymphoma [34]. The original M yc5 tumor was Pax5-positive, but upon culturing in vitro, Pax5 expression was spontaneously extinguished and B-cell markers were lost. Instead, the cultured cells readily engulfed latex beads and provided T-cell help such as bona fide macrophages [35]. N evertheless, upon re-expression of Pax5, M yc5 neoplastic cells expressed both surface IgM and surface IgD [36], which is characteristic of mature B cells (the so-called fraction $F$ [37]). We reasoned that this system is well-suited to test the role of $B C R$ signaling in Pax5-assisted lymphomagenesis.

Antigen presentation \& neoplastic transformation

To analyze the immediate effects of Pax5 on $B$ lymphomagenesis, we generated M yc5 subclones expressing the hydroxytamoxifen $(40 \mathrm{H} \mathrm{T})$ inducible variant of Pax5. U pon reinjection into syngeneic recipients, these clones formed much larger tumors in $40 \mathrm{HT}$-treated than in control mice [25]. To reveal the mechanism of Pax5-dependent lymphomagenesis, we profiled mRN As in Pax5-sufficient and -deficient tumors. We discovered that the repertoire of Pax5-activated genes was highly enriched in components of $B C R$ signaling: I $\alpha$, CD 19 antigen, B-cell linker (BLN K), Bruton agammaglobulinemia tyrosine kinase (Btk), and so on. In addition, two crucial inhibitors of BCR signaling, CD 22 and paired-lg-like receptor $B$, were repressed. W hat role do all these genes play in B lymphomagenesis?
To answer this question, we used the fusion protein containing the cytoplasmic regions of $\lg \alpha$ and $\lg \beta$ and constitutively targeted this to the plasma membrane [38]. Transduction of parental Myc5 cells with the Ig $\alpha / \beta$ cassette resulted in strong stimulation of tumor growth. Conversely, forced expression of CD 22, which antagonizes BCR activity [39], completely canceled the effects of Pax5 on tumor growth. Similar attenuation of tumor growth could be achieved through the use of pharmacological inhibitors of Syk, a BCR-associated tyrosine kinase [25].

Future directions: Pax5 \& BCR as

therapeutic targets

It has been proposed that BCR signaling (liganddependent or -independent) can promote survival of neoplastic B-lymphoma cells, for instance, via activation of antiapoptotic $\mathrm{MCl} 1$ [40]. Increased BCR signaling was indeed observed in cultured B-lymphoid cells [41], and appeared to contribute to their growth [24]. $\mathrm{H}$ owever, the role of $B C R$ signaling in tumor growth in vivo only has been inferred from circumstantial evidence: its persistent expression in most non-H odgkin lymphomas, the retention of functional Ig alleles in lymphomas with IgH translocations and the discovery of autoreactive BCR in some neoplasms (reviewed in [42]).

'Given the contribution of Pax5 to BCR signa ling, it seems pla usible that Pax5 can only exert its oncogenic effects when this pathway is func tional.'

To determine whether our experimental findings might be applicable to spontaneous human lymphomas, Dr Teresa M arafioti's group stained tissue arrays of human DLCBLs for both PAX5 and phosphorylated BLN K, the key adaptor protein of activated BCR. Her group observed that all DCBCL tumors stained positively for PAX5 and approximately half were also positive for phosphorylated BLN K. Thus, BCR is likely to be constitutively activated in at least some human B-cell tumors, attesting to the important causative role of PAX5 in B lymphomagenesis.

\section{Acknowledgements}

The authors thank $\mathrm{Dr}$ Martin Carroll (University of Pennsylvania) for critical comments on this manuscript. 
Financial \& competing interests disclosure

The authors have no relevant affiliations or financial involvement with any organization or entity with a financial interest in or financial conflict with the subject matter or materials discussed in the manuscript. This includes employment, consultancies, honoraria, stock ownership or options, expert testimony, grants or patents received or pending, or royalties

No writing assistance was utilized in the production of this manuscript.

\section{Bibliography}

Papers of special note have been highlighted as either of interest $(\bullet)$ or of considerableinterest $(\bullet)$ to readers.

1. O 'N eil J, Look AT: M echanisms of transcription factor deregulation in lymphoid cell transformation. O ncogene 26(47), 6838-6849 (2007).

2. Cobaleda C, Schebesta A, D elogu A, Busslinger $M$ : Pax5: the guardian of $B$ cell identity and function. $\mathrm{N}$ at. Immunol. 8(5), 463-470 (2007).

- Most recent and comprehensive review of the roles that Pax5 plays in normal development and neoplastic disease.

3. Fuxa $M$, Busslinger $M$ : Reporter gene insertions reveal a strictly $B$ lymphoid-specific expression pattern of Pax5 in support of its B cell identity function. J. Immunol. 178(12), 8222-8228 (2007).

4. N utt SL, Eberhard D, H orcher $M$, Rolink AG, Busslinger $M$ : Pax5 determines the identity of $B$ cells from the beginning to the end of B-lymphopoiesis. Int. Rev. Immunol. 20(1), 65-82 (2001).

5. Kallies $\mathrm{A}, \mathrm{H}$ asbold J, Fairfax $\mathrm{K}$ et al.: Initiation of plasma-cell differentiation is independent of the transcription factor Blimp-1. Immunity 26(5), 555-566 (2007).

6. Lauring J, Schlissel M S: Distinct factors regulate the murine RAG -2 promoter in B- and T-cell lines. Mol. Cell Biol. 19(4), 2601-2612 (1999).

7. Kishi $\mathrm{H}$, Jin ZX, Wei XC et al.: Cooperative binding of $\mathrm{C}-\mathrm{M} \mathrm{yb}$ and Pax- 5 activates the RAG -2 promoter in immature $B$ cells. Blood 99(2), 576-583 (2002).

8. Fuxa M, Skok J, Souabni A, Salvagiotto G, Roldan $E$, Busslinger $M$ : Pax5 induces $V$ to-DJ rearrangements and locus contraction of the immunoglobulin heavy-chain gene. Genes D ev. 18(4), 411-422 (2004).

9. Zhang Z, Espinoza CR, Yu Z et al.: Transcription factor Pax5 (BSAP) transactivates the RAG -mediated $\mathrm{V}(\mathrm{H})$ )-toDJ $(H)$ rearrangement of immunoglobulin genes. $N$ at. Immunol. 7(6), 616-624 (2006).

10. Johnson K, Pflugh D L, Yu D et al.: B cell-specific loss of histone 3 lysine 9 methylation in the $\mathrm{V}(\mathrm{H})$ locus depends on Pax5. N at. Immunol. 5(8), 853-861 (2004).
11. U rbanek P, Wang ZQ, Fetka I, Wagner EF, Busslinger $M$ : Complete block of early B-cell differentiation and altered patterning of the posterior midbrain in mice lacking Pax5/BSAP. Cell 79(5), 901-912 (1994).

- Classical paper establishing the role of Pax5 in maintaining B-cell identity.

12. Hodawadekar $S$, Wei $F, Y u D$, Thomas-Tikhonenko A, Atchison $M$ : Epigenetic histone modifications do not control Igk locus contraction and intranuclear localization in cells with dual B cell-macrophage potential. J. Immunol. 177(9), 6165-6171 (2006).

13. Fitzsimmons $D, H$ odsdon $W, W$ heat $W$, M aira SM , Wasylyk B, H agman J: Pax-5 (BSAP) recruits Ets proto-oncogene family proteins to form functional ternary complexes on a B-cell-specific promoter. Genes D ev. 10(17), 2198-2211 (1996).

14. M onroe JG : ITAM -mediated tonic signalling through pre $B C R$ and $B C R$ complexes. $N$ at. Rev. Immunol. 6(4), 283-294 (2006).

15. Gonda $\mathrm{H}$, Sugai $\mathrm{M}, \mathrm{N}$ ambu $\mathrm{Y}$ et al.: The balance between Pax 5 and Id 2 activities is the key to AID gene expression. J. Exp. M ed. 198(9), 1427-1437 (2003).

16. O ppezzo P, Dumas G, Lalanne Al et al.: $D$ ifferent isoforms of BSAP regulate expression of AID in normal and chronic lymphocytic leukemia B cells. Blood 105(6), 2495-2503 (2005)

17. Cook JR, Aguilera N I, Reshmi-Skarja S et al.: Lack of PAX 5 rearrangements in lymphoplasmacytic lymphomas: reassessing the reported association with $\mathrm{t}(9 ; 14)$. $\mathrm{H}$ um. Pathol. 35(4), 447-454 (2004).

18. Busslinger $M, K$ Klix N, Pfeffer $P$ Graninger PG, Kozmik Z: D eregulation of PAX- 5 by translocation of the $E \mu$ enhancer of the IgH locus adjacent to two alternative PAX-5 promoters in a diffuse large-cell lymphoma. Proc. N atl Acad. Sci. USA 93(12), 6129-6134 (1996).

19. Iida $S, R$ ao $P H, N$ allasivam $P$ et al.: The $(9 ; 14)(p 13 ; q 32)$ chromosomal translocation associated with lymphoplasmacytoid lymphoma involves the PAX-5 gene. Blood 88(11), 4110-4117 (1996).

- Ref. 18 and 19 are first independent reports of translocations involving Pax5.
20. M orrison AM, Jager $U$, Chott $A$, Schebesta $M, H$ aas $O A$, Busslinger $M$ : D eregulated $\mathrm{PAX}-5$ transcription from a translocated I IH promoter in marginal zone lymphoma. Blood 92(10), 3865-3878 (1998).

21. Poppe B, D ePP, M ichaux $L$ et al.: $P A X 5 / I G H$ rearrangement is a recurrent finding in a subset of aggressive B-N H L with complex chromosomal rearrangements. Genes Chromosomes Cancer 44(2), 218-223 (2005).

22. Pasqualucci $L, N$ eumeister $P, G$ oossens $T$ et al.: $\mathrm{H}$ ypermutation of multiple proto-oncogenes in B-cell diffuse large-cell lymphomas. N ature 412(6844), 341-346 (2001).

-. First demonstration that the Pax5 gene is affected by somatic hypermutations in diffuse large B-cell lymphoma.

23. Alizadeh $A A$, Eisen $M B, D$ avis RE et al.: $D$ istinct types of diffuse large $B$-cell lymphoma identified by gene expression profiling. $N$ ature 403(6769), 503-511 (2000).

24. Gururajan $M$, Jennings $C D$, Bondada S: Cutting edge: constitutive $B$ cell receptor signaling is critical for basal growth of B Iymphoma. J. Immunol. 176(10), 5715-5719 (2006).

25. Cozma D, Yu D, H odawadekar $S$ et al.: PAX5 promotes lymphomagenesis through the stimulation of B-cell receptor signaling. J. Clin. Invest. 117(9), 2602-2610 (2007).

-. Recent reports from the authors' laboratory demonstrating that B cell receptor signaling is crucial for Pax5dependent $B$ lymphomagenesis.

26. Bousquet $M$, Broccardo $C, Q$ uelen $C$ et al.: A novel PAX5-ELN fusion protein identified in B-cell acute lymphoblastic leukemia acts as a dominant negative on wild-type PAX5. Blood 109(8), 3417-3423 (2007).

- D emonstrates that some Pax5 fusion proteins act as dominant-negative mutants to inhibit function of endogenous Pax5 in acute lymphoblastic leukemia.

27. Cazzaniga $G, D$ aniotti $M$, Tosi $S$ et al.: The paired box domain gene PAX5 is fused to ETV6/TEL in an acute lymphoblastic leukemia case. Cancer Res. 61(12), 4666-4670 (2001). 
28. M ullighan CG, G oorha S, Radtke I et al.: $G$ enome-wide analysis of genetic alterations in acute lymphoblastic leukaemia. $N$ ature 446(7137), 758-764 (2007).

-. Establishes that EBF 1 and Pax5 are the two most frequently mutated genes in acute lymphoblastic leukemia and that most of these mutations are loss-of-function.

29. Shaffer AL, Rosenwald A, Staudt LM : Lymphoid malignancies: the dark side of B-cell differentiation. $\mathrm{N}$ at. Rev. Immunol. 2(12), 920-932 (2002).

30. Staudt LM : It'sALL in the diagnosis. Cancer Cell 1(2), 109-110 (2002).

31. Souabni A, Jochum W, Busslinger $M$ : O ncogenic role of Pax5 in the T-lymphoid lineage upon ectopic expression from the immunoglobulin heavy-chain locus. Blood 109(1), 281-289 (2006).

- D emonstrates the propensity of Pax5 to transform $T$ cells when expressed in the germline.

32. Stuart ET, Kioussi $C$, Aguzzi A, Gruss P: PAX 5 expression correlates with increasing malignancy in human astrocytomas. Clin. Cancer Res. 1(2), 207-214 (1995).

33. Baumann Kubetzko FB, D i PC, M aag C et al.: The PAX5 oncogene is expressed in $\mathrm{N}$-type neuroblastoma cells and increases tumorigenicity of a S-type cell line. Carcinogenesis 25(10), 1839-1846 (2004).
34. Yu D, Thomas-Tikhonenko A: A non-transgenic mouse model for B-cell lymphoma: in vivo infection of p53-null bone marrow progenitors by a $\mathrm{M}$ yc retrovirus is sufficient for tumorigenesis. Oncogene 21(12), 1922-1927 (2002).

35. H odawadekar S, Yu D, Freedman B, Sunyer $\mathrm{O} O$, Atchison $M$, Thomas-Tikhonenko A: B-lymphoma cells with epigenetic silencing of Pax5 transdifferentiate into macrophages, but not other hematopoietic lineages. Exp. Cell Res. 313(2), 331-340 (2007).

36. Yu D, Allman D, Goldschmidt $M$, Atchison $M, M$ onroe JG, ThomasTikhonenko A: 0 scillation between B-lymphoid and myeloid lineages in $M$ yc-induced hematopoietic tumors following spontaneous silencing/reactivation of the EBF/Pax5 pathway. Blood 101(5), 1950-1955 (2003).

37. H ardy RR, Carmack CE, Shinton SA, Kemp JD, H ayakawa K: Resolution and characterization of pro-B and pre-pro-B-cell stages in normal mouse bone marrow. J. Exp. M ed. 173(5), 1213-1225 (1991).

38. Bannish $G$, Fuentes-Panana EM , Cambier JC, Pear WS, M onroe JG: Ligand-independent signaling functions for the B-lymphocyte antigen receptor and their role in positive selection during $B$ lymphopoiesis. J. Exp. M ed. 194(11), 1583-1596 (2001).
39. N itschke L: The role of CD 22 and other inhibitory co-receptors in B-cell activation. Curr. O pin. Immunol. 17(3), 290-297 (2005).

40. Petlickovski A, Laurenti L, Li X et al.: Sustained signaling through the B-cell receptor induces $\mathrm{M} \mathrm{Cl}-1$ and promotes survival of chronic lymphocytic leukemia B cells. Blood 105(12), 4820-4827 (2005).

41. Irish J M , Czerwinski DK, N olan GP, Levy R: Altered B-cell receptor signaling kinetics distinguish human follicular lymphoma B cells from tumor infiltrating non-malignant B cells. Blood 108(9), 3135-3142 (2006).

42. Kuppers R: M echanisms of B-cell lymphoma pathogenesis. $\mathrm{N}$ at. Rev. Cancer 5(4), 251-262 (2005).

\section{Affiliations}

- Andrei ThomasTikhonenko D epartment of Pathobiology and M ari Lowe Center for Comparative O ncology, School of Veterinary M edicine, U niversity of Pennsylvania, Philadelphia PA 19104-6051, U SA

Tel.: +1 2155735138

Fax: +12157460380

andreit@mail.vet.upenn.edu

- Diana Cozma

Envision Pharma, Inc., 123 South Broad Street, Suite 1670, Philadelphia PA 19109, USA

Tel.: +1 2152396605

Fax: +1 2155450240

Diana.Cozma@envisionpharma.com 